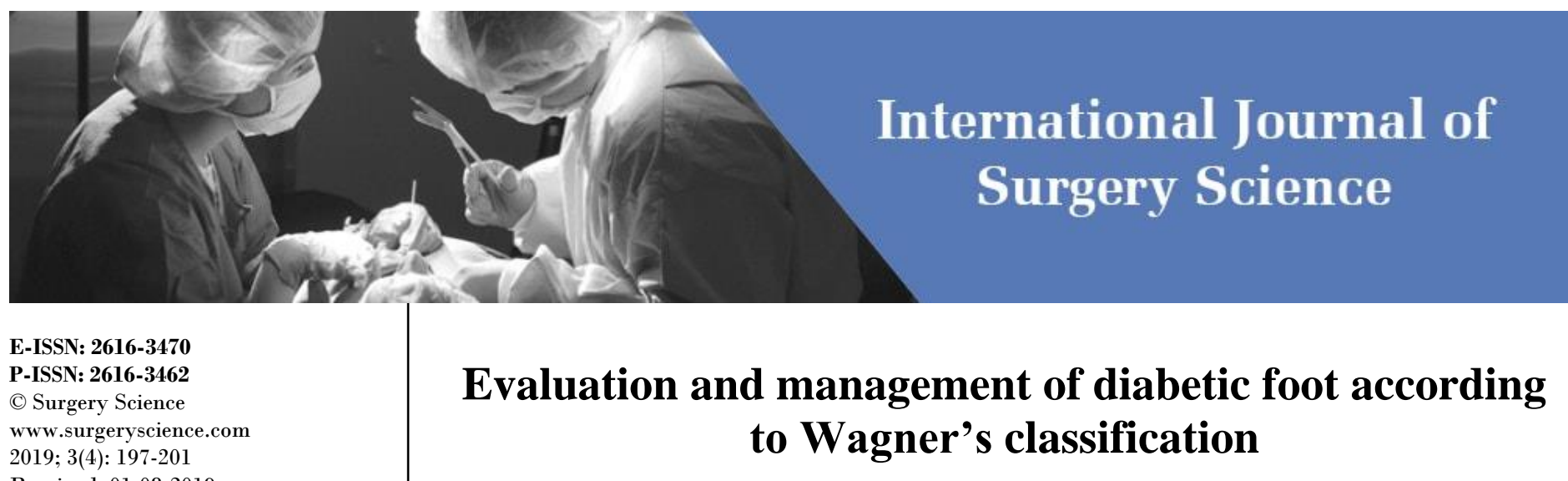

Received: 01-08-2019

Accepted: 03-09-2019

Dr. Sudatta Waghmare

Assistant Professor, Department of

Surgery, TN Medical College,

Mumbai, Maharashtra, India

\section{Dr. Harshal Meshram}

Senior Resident, Department of

Surgery, TN Medical College,

Mumbai, Maharashtra, India

\section{Dr. Rajesh Mahey}

Associate Professor, Department of

Surgery, TN Medical College,

Mumbai, Maharashtra, India

\section{Dr. Tilakdas Shetty}

Professor, Department of Surgery,

K J Somaiya Medical College,

Mumbai, Maharashtra, India

\section{Dr. Aman Singh}

Junior Resident, Department of

Surgery, TN Medical College,

Mumbai, Maharashtra, India
Corresponding Author:

Dr. Rajesh Mahey

Associate Professor, Department of

Surgery, TN Medical College,

Mumbai, Maharashtra, India

\section{Dr. Sudatta Waghmare, Dr. Harshal Meshram, Dr. Rajesh Mahey, Dr. Tilakdas Shetty and Dr. Aman Singh}

DOI: https://doi.org/10.33545/surgery.2019.v3.i4d.239

\begin{abstract}
Aims and Objectives: To re-evaluate role of Wagner's classification in the Study and Management of diabetic Foot in patient admitted to tertiary care hospital.

Materials and Methods: This hospital based observational study was conducted in the department of General Surgery at tertiary care hospital from July 2017 to August 2018. This study included 47 cases of Diabetic foot patients in which management protocol according to Wagner's Classification was studied. Data was collected from hospital records which includes history, physical examination, investigations, treatment and follow up at discharge was collected.

Results: The most common age of presentation in patients with diabetic foot lesion was between 41-60 yrs. In this study, out of 47 patients, 32 patients $(68.1 \%)$ were male and 15 patients $(31.9 \%)$ were female. The most common site was foot in 29 patients $(61.7 \%)$. Out of 47 cases studied, 28 cases were having history of trauma, which account for $59.6 \%$ of the total cases. Amputation was the most common treatment modality. In this study of 47 patients, 11 patient required local debridement after initial surgery. Out of 47 cases; 42 patients ulcers were healed, 5 patients ulcer were not healed (4\%).

Conclusion: Diabetic patients have always suffered from complication affecting the lower limbs. Foot infection and subsequent amputation of lower extremities are the most common cause of hospitalization among diabetic foot patients. Prevention strategy including patient's education in foot care, prophylactic skin and nail care, and footwear reduces the risk of foot ulceration and lower limb amputation by $25 \%$.
\end{abstract}

Keywords: Management, diabetic foot according, Wagner's classification

\section{Introduction}

Diabetes is a common disease affecting about $2.4 \%$ in rural and $4 \%-11.6 \%$ in urban dwellers in India ${ }^{[1]}$. India has highest prevalence of diabetes in world and accounts for almost $1 / 6$ of the diabetic patients. Approximately $10 \%-25 \%$ of all diabetics will develop some foot complications during the course of illness from simple calluses to major abscesses and osteomyelitis. Several classifications exist for grading ulceration and their management; however Wagner's classification is the simplest, best known for evaluation and management of diabetic foot ulceration ${ }^{[2]}$. Relative Risk of leg amputation is 40 times higher among person with diabetes than with those not diabetic. Moreover, up to $50 \%$ of diabetic amputees will undergo a second leg amputation within 5 years of initial amputation.

Complications involving the foot cause significant pain and suffering, loss of productive time, hospitalization, heavy expenses to the patient, community and nation as well. To add to above vascular insufficiency and neuropathy accompanying the diabetic foot most often necessitate amputation of the limb ${ }^{[3]}$.

In India habits like walking barefooted, lack of knowledge regarding diabetic foot, hot climate leading to increased perspiration, poor hygiene, poor sanitation, diet poor in proteins, general poverty, lack of basic medical infrastructure, etc have worsened the problem. Lack of interest from medical and surgical faculty due to required hardwork for this field has added to the problem statement.

The management of diabetic foot is focused primarily on avoiding amputation of lower extremities. Hence early recognition and proper therapy of diabetic foot lesion may save diabetic foot and leg ${ }^{[1]}$. The amount of interest in the diabetic foot has increased tremendously over the past ten years. There continues to be great interest in the treatment and prevention of diabetic 
foot. Wagner's classification helps in correlating appropriate treatment to proper grade of lesion with better outcome ${ }^{[4]}$. Lesser grade lesion responds well to conservative treatment with antibiotics and debridement while those with higher lesion require some kind of amputation.

\section{Aims and Objectives}

1. To Re-evaluate role of Wagner's classification in the Study and Management of diabetic Foot in patient admitted to tertiary care hospital

2. To investigate the Surgical Strategy of Diabetic Foot and analyse the therapeutic efficacy.

\section{Materials and Methods}

This was hospital based observational study done in the department of General Surgery at tertiary care hospital from July 2017 to August 2018. This study included 47 cases of Diabetic foot patients in which management protocol according to Wagner's Classification was studied. Data including history, examination, routine blood investigations and imaging radiological, treatment modalities used for that particular patient was collected. Dressings were done as per unit protocol. The data of the 47 patients was collected, tabulated and outcomes are discussed. Patients were followed up for 3 months irrespective whether wound has healed or not. Patients with diabetic foot $>$ 18 years old. (Diabetic foot is usually defined as any inframalleolar infection in a person with type 2 diabetes mellitus (DM2) were included in the study. Non diabetic foot patients (like traumatic or other neuropathic ulcer) and Pregnant patients were excluded. Institutional ethics committee permission was taken. Data was collected from hospital records at tertiary care hospital and history, physical examination, investigations, treatment and follow up at discharge was collected.

\section{Results}

Table 1: Demographic profile

\begin{tabular}{|c|c|c|}
\hline Age group & Frequency & Percent \\
\hline$<40$ years & 5 & 10.6 \\
\hline 41-60 years & 35 & 74.5 \\
\hline$>60$ years & 7 & 14.9 \\
\hline \multicolumn{3}{|l|}{ Sex } \\
\hline Female & 15 & 31.9 \\
\hline Male & 32 & 68.1 \\
\hline \multicolumn{3}{|l|}{ Mode of presentation } \\
\hline Gangrene & 15 & 31.9 \\
\hline Ulcer & 9 & 19.1 \\
\hline Cellulites & 3 & 6.4 \\
\hline Abscess & 2 & 4.3 \\
\hline Mixed & 18 & 38.3 \\
\hline \multicolumn{3}{|l|}{ Site of lesion } \\
\hline Foot & 29 & 61.7 \\
\hline Toe & 18 & 38.3 \\
\hline \multicolumn{3}{|l|}{ H/o trauma } \\
\hline Yes & 28 & 59.6 \\
\hline No & 19 & 40.4 \\
\hline \multicolumn{3}{|c|}{ H/o previous Ulcer or gangrene } \\
\hline Yes & 17 & 36.2 \\
\hline No & 30 & 63.8 \\
\hline \multicolumn{3}{|l|}{ Addiction history } \\
\hline H/o smoking & 9 & 19.1 \\
\hline $\mathrm{H} / \mathrm{o}$ alcohol & 26 & 55.3 \\
\hline \multicolumn{3}{|l|}{ Duration of DM } \\
\hline Newly Diagnosed & 10 & 21.3 \\
\hline Old case of DM & 37 & 78.7 \\
\hline
\end{tabular}

In the present study, the most common age of presentation in patients with diabetic foot lesion was between 41-60 yrs. In this study, out of 47 patients, 32 patients $(68.1 \%)$ were male and 15 patients $(31.9 \%)$ were female. A study was carried out including 47 patients who were admitted with diabetic foot their mode of presentation was as follows- 15 cases (31.9\%) present with Gangrene, 9 cases $(19.1 \%)$ with Ulcer, 3 cases $(6.4 \%)$ with cellulites, 2 cases $(4.3 \%)$ with abscess and 18 cases $(38.3 \%)$ presented with mixed features. i.e. (Combination of above factors). The most common site was foot in 29 patients $(61.7 \%)$. In present study out of 47 cases studied, 28 cases were having history of trauma, which account for $59.6 \%$ of the total cases. In study of 47 patients, 30 patients had no previous history of ulcer/gangrene, which account for $63.8 \%$. In this study, 9 patients were smoker (19.1), and 26 patients were alcoholic $(55.3 \%)$ and rest 10 having no addiction. In this study, 10 patients $(21.3 \%)$ were newly diagnosed and 37 patients $(78.7 \%)$ were known diabetics. Maximum amputations were done in patients with old case of diabetic.

Table 2: Other clinical findings

\begin{tabular}{|c|c|c|}
\hline Blood sugar at admission & Frequency & Percent \\
\hline$<100$ & 7 & 14.9 \\
\hline $101-200$ & 32 & 68.1 \\
\hline$>200$ & 8 & 17 \\
\hline \multicolumn{3}{|l|}{ Osteomyelitis } \\
\hline Yes & 4 & 8.5 \\
\hline No & 43 & 91.5 \\
\hline \multicolumn{3}{|l|}{ Doppler } \\
\hline Normal (Nad) & 38 & 80.9 \\
\hline Vascular disease(PVD) & 9 & 19.1 \\
\hline \multicolumn{3}{|l|}{ Organism } \\
\hline Pseudomonas & 15 & 31.9 \\
\hline Staphylococcus & 8 & 17 \\
\hline E.Coli & 7 & 14.9 \\
\hline Klebsiella & 5 & 10.6 \\
\hline Clostridium & 4 & 8.5 \\
\hline Negative & 8 & 17 \\
\hline \multicolumn{3}{|l|}{ Wagner's class } \\
\hline Grade 1 & 7 & 14.9 \\
\hline Grade 2 & 7 & 14.9 \\
\hline Grade 3 & 6 & 12.8 \\
\hline Grade 4 & 18 & 38.3 \\
\hline Grade 5 & 9 & 19.1 \\
\hline
\end{tabular}

In this study, 7 patients [14.9\%] having blood sugar $<100 \mathrm{mg} / \mathrm{dl}$, 32 patients [68.1\%] having sugar $101-200 \mathrm{mg} / \mathrm{dl}$ and 8 patients [17\%] having blood sugar $>200 \mathrm{mg} / \mathrm{dl}$. In this study of 47 patients, 4 patients $(8.5 \%)$ having bone involvement (osteomyelitis). In present study, 9 patients [19.1\%] had history of peripheral vascular disease (PVD). In this study of 47 patients, wound swab was send preoperatively and postoperatively which shows pattern of Causative organism.15 patients had pseudomonas, 8 patients had staphylococcus, 7 patients had E.coli, 5 patients had Klebsiella, 4 patients had Clostridium and 8 patients had Negative wound swab. Maximum patients present with grade 4 and 5 Wagner's lesion followed by Grade 1, Grade 2. As Ulcer is one of the most common presentations of Diabetic Foot. 
Table 3: Treatment details

\begin{tabular}{|c|c|c|}
\hline Treatment done & Frequency & Percent \\
\hline BK amputation with flap closure & 14 & 29.8 \\
\hline Debridement & 10 & 21.3 \\
\hline TMT amputation with flap closure & 8 & 17 \\
\hline Conservative & 7 & 14.9 \\
\hline Toe amputation with flap closure & 6 & 12.8 \\
\hline I and D of abscess & 2 & 4.3 \\
\hline Re-surgery & & \\
\hline Yes & 11 & 23.4 \\
\hline No & 36 & 76.6 \\
\hline Follow up after 3 months & & \\
\hline Healed & 42 & 89.4 \\
\hline Unhealed & 5 & 10.6 \\
\hline
\end{tabular}

Amputation was the most common treatment modality among various treatment modalities. In this study of 47 patients, 11 patient required local debridement after initial surgery. In this study of 47 patients, who were presented with diabetic foot and undergone amputation; 42 patients ulcers were healed, 5 patients ulcer were not healed (4\%).

Table 4: Comparison of various parameters with outcome at follow up of 3 months

\begin{tabular}{|c|c|c|c|c|c|}
\hline & & \multicolumn{2}{|c|}{ Follow up after 3 months } & \multirow{2}{*}{ Total } & \multirow{2}{*}{$P$ value } \\
\hline & & Healed & Unhealed & & \\
\hline \multirow{2}{*}{ Age[yrs] } & $<60$ years & $40(95.2 \%)$ & $0(0 \%)$ & $40(85.1 \%)$ & \multirow{2}{*}{0.0001} \\
\hline & $>60$ years & $2(4.8 \%)$ & $5(100 \%)$ & $7(14.9 \%)$ & \\
\hline \multirow{2}{*}{ Osteomyelitis } & Yes & $4(9.5 \%)$ & $0(0 \%)$ & $4(8.5 \%)$ & \multirow{2}{*}{0.471} \\
\hline & No & $38(90.5 \%)$ & $5(100 \%)$ & $43(91.5 \%)$ & \\
\hline \multirow{2}{*}{ H/o smoking } & Yes & $5(11.9 \%)$ & $4(80 \%)$ & $9(19.10 \%)$ & \multirow{2}{*}{0.0001} \\
\hline & No & $37(88.1 \%)$ & $1(20 \%)$ & $38(80.90 \%)$ & \\
\hline \multirow{2}{*}{ Blood sugar at admission } & $<200$ & $39(92.9 \%)$ & $0(0 \%)$ & $39(83 \%)$ & \multirow{2}{*}{0.0001} \\
\hline & $>200$ & $3(7.1 \%)$ & $5(100 \%)$ & $8(17 \%)$ & \\
\hline \multirow{2}{*}{ Doppler } & PVD & $5(11.9 \%)$ & $4(80 \%)$ & $9(19.1 \%)$ & \multirow{2}{*}{0.0001} \\
\hline & Normal & $37(88.1 \%)$ & $1(20 \%)$ & $38(80.9 \%)$ & \\
\hline \multirow{2}{*}{ Re-surgery } & Yes & $7(16.7 \%)$ & $4(80 \%)$ & $11(23.4 \%)$ & \multirow{2}{*}{0.002} \\
\hline & No & $35(83.3 \%)$ & $1(20 \%)$ & $36(76.6 \%)$ & \\
\hline \multicolumn{2}{|l|}{ Total } & $42(100 \%)$ & $5(100 \%)$ & $47(100 \%)$ & \\
\hline
\end{tabular}

\section{Discussion}

Diabetes is global health crises, which result in major economic consequences for patient, their family and the society. The International Diabetes Federation (IDF) Atlas reported that the number of people with diabetes was approximately 366 million in 2011, and by the year 2030 this number would rise to 552 million ${ }^{[5]}$. Diabetic foot is a serious and extensive complication with considerable morbidity that affects $15 \%$ of patient with the diabetes during their lifetime ${ }^{[6]}$.

This study carried out from July 2017 to August 2018 in tertiary care centre which includes 47 patients admitted with diabetic foot and managed according to Wagner's classification.

Age: Age distribution of 47 cases studied in Nair Hospital, Mumbai. Youngest patient was 30 years old and eldest patient is 80 years old. Highest numbers of cases were found in the age group of 41-60 yrs. As compared to study conducted by "Roohulmuqim" majority of our cases are in 51-60years of age whereas in their study majority of cases were in 41-50 years of age group. Also there is positive association between the age and incidence of diabetic foot. Age more than 60 is more prone for diabetic foot and non healing ulcer ${ }^{[7]}$.

Out of the 47 cases studied 32 cases are males and 15 cases are females. Male to female ratio is 2.13 . As compared to study by "Rooh-ul-muqim" there are more male patients and less female patients observed in our study. Higher incidence of diabetic foot in males may be due to the exposure to injuries during their work, which subsequently leads to injury mostly to the insensitive foot ${ }^{[7]}$.

Nature of the lesion-of the 47 cases studied mixed $38.3 \%$ was the most common presentation followed by gangrene $31.9 \%$, ulcer $19.1 \%$, cellulitis $6.4 \%$, and abscess was $4.3 \%$, of the patients. Osteomyelitis was seen in $8.5 \%$ of the patients. In this study, osteomyelitis was not significantly associated with diabetic foot.

Among 47 cases, the most common site includes foot in 29 patients (61.7), toe in 18 patients (38.3). As per Apelquist study series in1988 dorsum of foot is most common site ${ }^{[8]}$.

Among 47 patients, 28 patients $(59.6 \%)$ had history of trauma. In Reiber et al. series $77 \%$ patients had history of trauma. ${ }^{9}$ Repetitive unrecognised trauma and abnormal distributions of pressure are principle factor in causing foot ulcer leading to gangrene ${ }^{[10]}$.

Rate of amputation: In our study amputation for diabetic foot complication was more than $50 \%$.

Another multi centric study involving 31 study sites across India reported that major amputations comprised about $29.1 \%$ and minor amputation $70.9 \%$ among the diabetic patients with foot infection. This study also observed that infection was the significant cause for the amputation in approximately $90 \%$ of study population ${ }^{[11]}$.

In this study of 47 patients with diabetic foot who underwent amputation, 17 patients (36.2) had previous history of ulcer or gangrene. This indicates that history of previous Ulcer/ Gangrene has significant role in patient with diabetic foot.

In the present study of 47 patients, 9 patients are smoker (19.1) and 26 patients are alcoholic (55.3) while rest doesn't have any addiction. Shivkumar S, Verma AK, Bal A, Sudaram KR also mention smoking, alcohol and tobacco are risk factors for 
diabetic foot ulcer. This indicates that those patients with diabetes having addiction of alcohol and smoking are more prone to develop a vasculopathy and diabetic foot complication which leads to amputation. In our study also, smoking has significant association with diabetic foot ${ }^{[12]}$.

In this study, 10 patients $(21.3 \%)$ are newly diagnosed and 37 were known diabetics (78.7\%). Maximum no of amputations are carried out in patient with duration of diabetes $>10$ years, which contribute $37 \%$. Mayfield JA reported that duration of diabetes has definite correlation with foot lesion. Duration of diabetes shows an important association with diabetes related complication like neuropathy, vasculopathy ${ }^{[13]}$.

In the present study of 47 patients, 7 patients $(14.9 \%)$ had blood sugar $<100 \mathrm{mg} / \mathrm{dl}$. 32 patients $(68.1 \%)$ had blood sugar between $101-200 \mathrm{mg} / \mathrm{dl}$. 8 patients $(17 \%)$ had blood sugar $>200 \mathrm{mg} / \mathrm{dl}$. This indicates that uncontrolled diabetes leads to increased severity of infection and ends up with amputation. In this study, blood sugar at admission had significant outcome on diabetic foot.

In this study of 47 patients, 4 patients (8.5\%) having bone involvement such as Charcot's foot/ osteomyelitis. In Palena LM, Brocco E and Ninkovic S study series in 2013: $10 \%$ patients affected by ischemic Charcot's neuroarthropathy required below-the-knee amputation. Osteomyelitis is present in many diabetic foot ulcers. Demineralisation, periosteal reaction and bony destruction are the classical radiographic triad of osteomyelitis appearing only after $30-50 \%$ of bone destruction, a process that takes up to weeks. After infected bone is removed, the patient required only antibiotics for the control of bacteria in the surrounding soft tissue ${ }^{[14]}$.

In the present study of 47 patients, the incidence of vascular disease is present in $19.1 \%$ of patients. Walters DP study shows incidence of PVD is $57-24.2 \%{ }^{[15]}$. Micro angiography, the characteristic feature of diabetic vasculopathy accounts for the higher frequency of small patchy lesion of gangrene. This has been supported by Pecoraro RE and Gibson GW in their study. In this study vascular disease (PVD) shows significance with the outcome of diabetic foot ${ }^{[16]}$. This may be explained by the fact that majority of lesions admitted were gangrene or non healing ulcers which are sequale of vasculopathy. Prolonged duration of diabetes, male predominance, associated habits like smoking further add to increase the prevalence of peripheral vascular disease in these patients.

Duration of diabetes, smoking and hyperglycemia were the most important factors responsible for development of peripheral vascular disease. Of patients having peripheral vascular disease duration of diabetes more than 10 years and hyperglycemia were statistically most important factors.

In this study, wound swab was sent for microbiological culture and sensitivity. From 15 patients (31.9\%) Pseudomonas aeruginosa was isolated; from 8 patients (17\%) Staphylococcus aureus was isolated, from 7 patients (14.9\%) E. Colli was isolated, from 5 patients $(10.6 \%)$ Klebsiella was isolated and from 4 patients $(8.5 \%)$ Clostridium was isolated. Study in patients with diabetic foot in India reported that polymicrobial infection was found in $35 \%$ of patient ${ }^{[16]}$. Infection is a major factor in the pathogenesis of diabetic foot and associated with ischemia leads to amputation.

Lesions according to Wagner's classification-Majority of the patients are in grade IV lie $38.3 \%$ of the patients. In grade 1 $14.9 \%$, grade II $14.9 \%$, grade III $12.8 \%$ and grade V $19.1 \%$ is observed. Study conducted by "Rooh-ul-muqim" majority of the cases was in Grade 11 and 111 as compared to present study where majority of patients are in Grade IV and II ${ }^{[7]}$.
In the present study, $15 \%$ of the individuals improved with conservative management and majority patients $85 \%$ were subjected to surgical intervention. Compared to "Rooh-ulmuqim" $50 \%$ of our patient underwent disarticulation or amputation compared to $48 \%$ in their study. Only $15 \%$ of our patient improved with conservative management indicating that surgery is the main line of management inpatient with diabetic foot ${ }^{[7]}$.

In the present study of 47 patients, 11 patients required repeat surgery $(23.4 \%)$ Need for re surgery either in the form of local debridement or amputation has significant on the outcome of diabetic foot.

In the study of 47 patients, who admitted with diabetic foot and undergone amputation, $89 \%$ patients ulcer healed within 3 months. In Rooh-ul-muqim et al. study out of 100 patients 96 discharged and 4 expired ${ }^{[7]}$.

\section{Conclusion}

Foot ulceration in diabetic patients is resource consuming, disabling morbidity, and often the first step towards lower extremity amputation. Prevention is the best treatment. Wagner's classification helps in correlating appropriate treatment to proper grade of lesion with better outcome. Lesser grade lesions respond well to conservative treatment with antibiotics and debridement while those with higher lesions require some kind of amputation. Effective glycaemic control and education are of key importance for decreasing diabetic foot disease. With early presentation and hospital admission, aggressive medical and surgical treatment according to the grade of the disease can improve outcome and reduce the morbidity and mortality due to diabetes.

\section{References}

1. Connor H Some Historical Aspects of Diabetic Foot Disease. Diabetes Metab Res Rev. 2008; 24(1):S7-S13.

2. Pryce TD: A Case of Perforating Ulcers of Both Feet Associated with Diabetes and Ataxic symptoms. Lancet. $1887 ; 11: 11-2$.

3. Park SY, et al. Effects of foot complications in patients with Type 2 diabetes mellitus on public healthcare: An analysis based on the Korea National Diabetes Program Cohort. J Diabetes Complications. 2016; 16:30253-7.

4. Joshi SR, Parikh RM. India - Diabetes Capital of the World: Now Heading Towards Hypertension. J Assoc Physicians India. 2007; 55:323-4.

5. International Diabetes Federation, Diabetes Atlas, 5th Edition, 2012.

6. Holroyde CP, Reichard GA Jr. General Metabolic Abnormalities in Cancer Patients: Anorexia and Cachexia. SurgClin North Am. 1986; 66(5):947-56.

7. Rooh-Ul-Muqim, Ahmed M, Griffin S. Evaluation and Management of Diabetic Foot According To Wagner's Classification. A Study of 100 Cases. J Ayub Med Coll Abbottabad. 2003; 15(3):39-42.

8. Carter DM, Lin AN. Wound Healing And Epidermolysis Bullosa. Arch Dermatol. 1988; 124(5):732-3.

9. Baker RWR, Ward DJ. Effect of Blood Glucose Control on the Accumulation of Sorbitol in Nervous System. Diabetes Swartz's Principles of Surgery 10th Edition Pg 219. 1972; 21:1173-78.

10. Qari FA, Akbar D. Diabetic Foot: Presentation and Treatment. Saudi Med J. 2000; 21(5):443-6.

11. Chellan G, Srikumar S, Varma AK, Mangalanandan TS, Sundaram KR, Jayakumar RV et al. Foot Care Practice - 
The Key To Prevent Diabetic Foot Ulcers In India. Foot (Edinb). 2012; 22(4):298-302.

12. Mayfield JA, Reiber GE, Sanders LJ, Janisse D, Pogach LM; American Diabetes Association. Preventive Foot Care in Diabetes. Diabetes Care. 2004; 27(1):S63-4.

13. Palena LM, Brocco E, Ninkovic S, Volpe A, Manzi M. Ischemic Charcot foot: different disease with different treatment? J Cardiovasc Surg (Torino). 2013; 54(5):561-6.

14. Walter DP, Gatting W, Mullee MA, et al. The prevalence of diabetics and non-diabetic subjects in an English community. Diab Medicine. 1992; 9:710-15.

15. Pecoraro RE, Reiber GE, Burgess EM. Pathways to Diabetic Limb Amputation. Basis for Prevention. Diabetes Care. 1990; 13(5):513-21. 